\title{
Review: anticholinergic drugs improve symptoms but increase dry mouth in adults with overactive bladder syndrome
}

Hay-Smith J, Herbison P, Ellis G, et al. Anticholinergic drugs versus placebo for overactive bladder syndrome in adults. Cochrane Database Syst Rev 2002;(3):CD003781 (latest version May 29 2002).

\section{QUESTION: What are the effects of anticholinergic drugs in adults with overactive bladder syndrome?}

\section{Data sources}

Studies were identified by searching the Cochrane Incontinence Group trials register (to January 2002) and reference lists of relevant papers.

\section{Study selection}

Randomised or quasi-randomised controlled trials in adults with symptomatic diagnosis of overactive bladder syndrome, urodynamic diagnosis of detrusor overactivity, or both, that compared an anticholinergic drug (given to decrease symptoms of overactive bladder) with placebo or no treatment. Studies of darifenacin, emepronium bromide or carrageenate, dicyclomine chloride, oxybutynin chloride, propiverine, propantheline bromide, tolterodine, and trospium chloride were included. Studies of terodiline or drugs with less direct anticholinergic effects were excluded.

\section{Data extraction}

Data were extracted by 2 independent reviewers for trial quality, participants, interventions, and outcomes.

\section{Main results}

51 studies (32 parallel arm studies, $\mathrm{n}=6124$ adults and 19 crossover studies, $\mathrm{n}=589$ adults) were included. All parallel arm studies compared anticholinergic drugs with placebo. In 4 parallel arm studies, intravesical administration was used, and in the remaining studies, drugs were taken orally (range of treatment duration 12 $\mathrm{d}$ to $12 \mathrm{wks}$ ). The crossover studies (range of treatment duration 1 dose to $6 \mathrm{wks}$ ) did not present data in a way that allowed inclusion in a meta-analysis. All but 1 study was double blind. In 13 studies, analysis was by intention to treat.

Meta-analysis of parallel arm studies showed that patients who received anticholinergic drugs were more likely to report an improvement or cure in symptoms and had fewer leakage episodes in 24 hours, fewer micturitions in 24 hours, increased maximum cystometric volume, increased volume at first contraction, and increased residual volume than those who received placebo. However, they were also more likely to report having a dry mouth (table). In 13 parallel arm studies, anticholinergic drugs and placebo did not differ for rates of withdrawal because of adverse effects.

\section{Conclusion}

In adults with overactive bladder syndrome, anticholinergic drugs improve symptoms but are associated with increased dry mouth.
Parallel arm studies of anticholinergic drugs $v$ placebo for overactive bladder syndrome in adults at 12 days to 12 weeks*

\begin{tabular}{|c|c|c|c|c|}
\hline \multirow[b]{2}{*}{ Outcomes } & \multicolumn{2}{|c|}{ Weighted event rates } & \multirow[b]{2}{*}{ RBI $(95 \%$ CI) } & \multirow[b]{2}{*}{ NNT (CI) } \\
\hline & $\begin{array}{l}\text { Anticholinergic } \\
\text { drugs }\end{array}$ & Placebo & & \\
\hline \multirow[t]{2}{*}{$\begin{array}{l}\text { Self reported cure or } \\
\text { improvement (8 studies) }\end{array}$} & $63 \%$ & $45 \%$ & $41 \%(29$ to 54$)$ & $6(5$ to 8$)$ \\
\hline & & & RRI (Cl) & NNH (Cl) \\
\hline Dry mouth (20 studies) & $36 \%$ & $15 \%$ & 138 (70 to 232$)$ & 5 (4 to 7$)$ \\
\hline \multicolumn{2}{|l|}{ Outcomes } & \multicolumn{3}{|c|}{ Weighted mean difference $(\mathrm{Cl})$} \\
\hline \multicolumn{2}{|c|}{$\begin{array}{l}\text { Number of leakage episodes in } 24 \text { hours ( } 9 \\
\text { studies) }\end{array}$} & \multicolumn{3}{|c|}{$-0.56(-0.73$ to -0.39$)$} \\
\hline \multicolumn{2}{|c|}{ Number of micturitions in 24 hours ( 8 studies) } & \multicolumn{3}{|c|}{$-0.59(-0.83$ to -0.36$)$} \\
\hline \multicolumn{2}{|c|}{ Maximum cystometric volume $(\mathrm{ml})$ (12 studies) } & \multicolumn{3}{|c|}{$54.3(43.0$ to 65.7$)$} \\
\hline \multicolumn{2}{|c|}{ Volume at first contraction (ml) (9 studies) } & \multicolumn{3}{|c|}{$52.3(37.5$ to 67.1$)$} \\
\hline \multicolumn{2}{|c|}{ Residual volume (ml) (11 studies) } & \multicolumn{3}{|c|}{$4.1(0.73$ to 7.4$)$} \\
\hline
\end{tabular}

*Abbreviations defined in glossary; RBI, RRI, NNT, NNH, and $\mathrm{Cl}$ calculated from data in article.

\section{COMMENTARY}

Symptoms of overactive bladder syndrome include urgency (with or without urge incontinence), usually in combination with frequency or nocturia or both. About $16 \%$ of adults report having symptoms of an overactive bladder, and this prevalence increases with age. ${ }^{1-2}$ The treatment options for overactive bladder include conservative treatment (eg, bladder training, electrical stimulation, behaviour modification), pharmacotherapy (eg, use of anticholinergic drugs), or both. This comprehensive systematic review by Hay-Smith et al only considers the use of anticholinergic medications.

The reviewers conclude that use of anticholinergic medication for overactive bladder syndrome results in a statistically significant improvement in symptoms. However, this improvement translates into 1 less void and 1 less episode of leakage over a 48 hour period. Also, a large placebo effect was seen, with $45 \%$ in the placebo group reporting cure or improvement, likely a result of completing urinary diaries. The question then is, how clinically meaningful are these results? The reviewers note that it is unclear to what extent the observed effects translate into benefits that are important to people with overactive bladder syndrome, such as quality of life. Dry mouth is noted as the major side effect, but little evidence is available about what the long term effects, if any, might be.

From a nursing perspective, it is important to counsel patients with overactive bladder syndrome about the limited benefits of anticholinergic medications; the risk of side effects, in particular, dry mouth; the absence of information about the long term effects of these drugs; and alternative more conservative interventions such as caffeine reduction and urge suppression.

Jennifer Skelly, RN, PhD

Associate Professor, School of Nursing, McMaster University Director, Continence Program, St Joseph's Health Care, Hamilton, Ontario, Canada

1 Milsom I, Abrams P, Cardozo L, et al. How widespread are the symptoms of an overactive bladder and how are they managed? A population-based prevalence study. BJU Int 2001;87:760-6.

2 Hampel C, Wienhold D, Benken N, et al. Definition of overactive bladder and epidemiology of urinary incontinence. Urology 1997;50:4-14. 